\title{
Evaluation of immune response profiles of individuals with chronic Hepatitis C treated with interferon alpha and ribavirin, in the foundation of tropical medicine of Amazonas
}

Ana Ruth Araújo ${ }^{2^{*}}$, Liziara Silva Fraporti ${ }^{1,3}$, Kátia Luz Torres $^{1}$, João Paulo Diniz Pimentel ${ }^{1}$, Tatiane Amabile ${ }^{1}$, Andrea Tarragô ${ }^{1}$, Laura Patrícia Viana Maia ${ }^{1,3}$, Nadja Garcia ${ }^{1,3}$, Walter Luiz Neves ${ }^{1}$, Adriana Malheiro ${ }^{1,3}$

From $16^{\text {th }}$ International Symposium on HIV and Emerging Infectious Diseases

Marseille, France. 24-26 March 2010

\section{Background}

The HCV is considered the main etiological agent involved in the hepatitis parenteral transmission. The most frequent genotypes in Brazil are 1, 2 and 3, and genotype $1 \mathrm{~b}$ is the most frequent in blood donors. Data from the serological screening of the Foundation of Hematology and Hemotherapy of Amazonas (FHEMOAM) show that $0.32 \%$ of donors are seropositivity for anti-HCV. Some studies showed that 15 to $25 \%$ has good prognostic but $80 \%$ develops chronic hepatitis. The purpose study was to describe the clinical course and immunological profile of chronic infection by HCV in patients treated with interferon-alpha and ribavirin.

\section{Methods}

Clinical and laboratory evaluation, including viral genotype, viral load, and cellular and humoral immune response, during the first 24 weeks of therapy.

\section{Results}

Partial results showed that genotype 1 (51.72\%) is more prevalent in the Amazon, followed by 3 (31.03\%) and 2 (17.24\%). Significant changes of AST and ALT concentrations showed an increase in the 4 weeks of treatment. We observed a trend to increase cell populations in time 0 (pretreatment) to lymphocyte $(63.3 \pm 88.7)$, monocytes $(10.6 \pm 21.5)$, neutrophils $(86.7 \pm 126,1)$, had not statistically significant difference. The analysis by flow cytometry showed an increase in total T cells and CD4 + in 4 weeks, returning to baseline at 12 and 24 weeks after treatment. Furthermore, there was a decrease of LTCD8 + in 12 and 24 weeks after treatment.

\section{Discussion}

Partial results showed that $\mathrm{HCV}$ infection changes the profile of immune response in treated of patients with Interferon-alpha and ribavirin.

\section{Financial support \\ CNPq; FAPEAM.}

\section{Author details \\ ${ }^{1}$ Fundação de Hematologia e Hemoterapia do Amazonas, Manaus, Brazil. ${ }^{2}$ Fundação de Medicina Tropical do Amazonas, Manaus, Brazil. ${ }^{3}$ Universidade do Amazonas, Manaus, Brazil.}

Published: 11 May 2010
doi:10.1186/1742-4690-7-S1-P31
Cite this article as: Araújo et al.: Evaluation of immune response profiles of individuals with chronic Hepatitis $C$ treated with interferon alpha and ribavirin, in the foundation of tropical medicine of Amazonas. Retrovirology 2010 7(Suppl 1):P31.

* Correspondence: elisadleon@yahoo.com.br

${ }^{2}$ Fundação de Medicina Tropical do Amazonas, Manaus, Brazil 